Universitas, Volumen 1, Año 1, 2007, 27-32

(C) 2007 UNAN-León, Editorial Universitaria

\title{
Resistencia antimicrobiana en Hospitales nor-occidentales de Nicaragua
}

\author{
Karen Herrera², Meylin Espinoza², Yaoli Mejía², Luis Enrique Zambrana², Erasmo Silva², Jency Rojas², \\ Walter Gadea ${ }^{2}$, Sergio Chavarría ${ }^{3}$, Mario Hernández³, Ma. Mercedes Ramirez ${ }^{3}$, Juana Ma. Membreño ${ }^{4}$, Ma. \\ Eugenia Lara ${ }^{4}$, J. E. Saenz ${ }^{5}$, S. Valle ${ }^{4}$, A. Torrez $^{4}$, y E. Carera ${ }^{1}$, Mercedes Cáceres ${ }^{1 *}$. \\ Centro de Investigación de Enfermedades Infecciosas (CEI), Facultad de Ciencias Médicas, Universidad Nacional \\ Autónoma de Nicaragua, León ${ }^{1}$; Hospital San Juan de Dios, Esteli ; Hospital M. Abdalah, Chinandega ${ }^{3}$; Hospital \\ España, Chinandega ; ; Departamento de Pediatría, Hospital Escuela Oscar Danilo Rosales Argüello, León ${ }^{4}$.
}

\section{RESUMEN}

\begin{abstract}
En los últimos años se ha observado un incremento de la incidencia de la Resistencia Antimicrobiana entre patógenos que causan infecciones intra-hospitalarias principalmente y también en la comunidad. La Resistencia antimicrobiana es un problema global de salud pública, promovido básicamente por el uso y abuso de los antibióticos. El fenómeno de la Resistencia antimicrobiana es un área prioritaria de investigación del Centro de investigación de enfermedades infecciosas y como parte de sus actividades se realizó un estudio en tres hospitales noroccidentales (León, Chinandega y Estelí) con el objetivo de conocer el perfil de resistencia o sensibilidad antimicrobiana de bacterias aerobias aisladas de pacientes que fueron atendidos en estos hospitales en el periodo comprendido entre Mayo 2003 a Mayo 2006 . Se incluyó en el estudio 1181 cepas de bacterias aerobias y se utilizó el método Kirby Bauer según recomendaciones del NCCLS, para determinar el perfil de resistencia. Las más frecuentes especies bacterianas estudiadas fueron, Estafilococos aureus (385 cepas), E. coli (209 cepas) , Pseudomona spp. (180 cepas) seguidas por un menor número de cepas de Shigella spp., Streptococos beta hemoliticos del grupo A y otros bacilos Gram negativos obtenidas principalmente de muestras biológicas de infecciones de piel y tejidos blandos, bacteriemia neonatal, infecciones de vías urinarias y Faringoamigdalitis. Los Resultados obtenidos fueron los siguientes: Penicilina fué el fármaco de menor efectividad contra E. aureus; un porcentaje importante mayor del 25\% fueron resistentes a Meticilina principalmente cepas de Estelí. Sin embargo estos antibioticos fueron altamente efectivos contra Streptococos, no se presentó resistencia a Vancomicina. En relaciòn a las bacterias Gram negativas, T. sulfa fue el antimicrobiano de menor efectividad contra E. coli aislados de urocultivos, con un porcentaje similar en los tres hospitales, e igualmente contra Klebsiella spp. y otros Gram negativos, excepto Pseudomona spp. para el que no esta indicado su análisis. Pseudomona spp. fue resistente principalmente a Cloranfenicol y Ceftriaxona en Estelí, a Ceftriaxona y Gentamicina en León y Chinandega. Los resultados de este estudio muestran la importancia del problema y ofrecen la posibilidad a la comunidad médica de utilizarlos para adecuar las pautas de tratamiento y contribuir a modificar conductas de riesgo que promueven la Resistencia antimicrobiana.
\end{abstract}

Palabras claves:

Resistencia antimicrobiana, Infecciones intra hospitalarias, Agentes infecciosos, Bacterias aerobias

\section{INTRODUCCIÓN}

En los últimos años uno de los aspectos más alarmantes en relación a las enfermedades infecciosas ha sido el dramático incremento en la incidencia de resistencia Antimicrobiana entre patógenos que causan infecciones intra-hospitalarias pero también entre los que lo hacen en la comunidad. ${ }^{[1]}$ Este incremento en la Resistencia Antimicrobiana es ahora un problema global y no existe país que sea inmune a este impacto. Importantes patógenos han adquirido resistencia al menos a un tipo de antibiótico y muchos casos se han convertido en bacterias multirresistentes. Este fenómeno es considerado actualmente un problema de salud pública, promovido básicamente por el uso indiscriminado de antibióticos en hospitales, clínicas, comunidad, agricultura, producción de alimentos; la magnitud del problema difiere de un país a otro e inclusive de un hospital a otro en un mismo país, por tanto es mandatorio el monitoreo continuo que permita generar resultados que puedan ser utilizados para el establecimiento de protocolos de manejo de las infecciones bacterianas en base a resultados generados localmente..$^{[2,3]} \mathrm{El}$ Centro de Investigación de Enfermedades infecciosas de la UNAN-León estableció dentro de sus áreas prioritarias de investigación el estudio de la Resistencia antimicrobiana. El principal objetivo de esta área de investigación es el estudio del perfil de resistencia antimicrobiana de los más importantes patógenos bacterianos causantes de procesos infecciosos y el análisis de los mecanismos de resistencia utilizando técnicas convencionales y moleculares. Esta área de investigación cuenta con la importante colaboración de Médicos y Bioanalistas Clínicos de los hospitales y Centros de Salud de León, Chinandega, Estelí, y estudiantes de la Facultad de Ciencias Médicas.

\footnotetext{
*Autor para correspondencia: mcaceres@unanleon.edu.ni, Merkaceres2001@yahoo.com.mx
} 


\section{MATERIALES Y MÉTODOS}

El estudio incluye 1.181 cepas de bacterias aerobias aisladas de pacientes con diferentes procesos infecciosos que fueron atendidos en los hospitales de León, Estelí y Chinandega.

Las cepas bacterianas de los hospitales de Estelí y Chinandega fueron aisladas en sus respectivos Laboratorios y luego transportadas a UNAN-León en un medio sólido (Bacto agar al 1\%) a temperatura ambiente. En el caso de León, estas fueron aisladas en los Laboratorios del CEI de la UNAN-León directamente de muestras biológicas de pacientes hospitalizados $\mathrm{y} /$ o de la Comunidad. A todos los pacientes de quienes procedían las cepas incluidas en el estudio se les lleno una ficha que contenía información relacionada con edad, sexo, diagnóstico clínico, estancia hospitalaria y uso previo de antibióticos.

En los Laboratorios del CEI de la UNAN- León, previo a la determinación de la susceptibilidad antimicrobiana todas las bacterias fueron reidentificadas por pruebas bioquímicas y análisis morfológicọ,Tinción de Gram; la prueba de difusión de discos en agar Kirby Bauer según recomendaciones del NCCLS. ${ }^{[4]}$ fue utilizada para la determinación del perfil de resistencia.

Los antimicrobianos analizados fueron: Ceftriaxona, Ceftazidima, Gentamicina, Ciprofloxacina, Norfloxacina, Trimetoprin sulfa para Gram negativos. Meticilina, Vancomicina y Eritromicina para Gram positivos.

Para el control de calidad se utilizaron las cepas de Streptococcus pneumoniae ATCC 49619, Staphylococcus aureus ATCC 29213, Escherichia coli ATCC 25922, y Pseudomonas aeruginosa ATCC 27853.

\section{RESULTADOS}

La frecuencia y distribución de las especies analizadas se observan en el Grafico No. 1. Las especies bacterianas más frecuentes fueron: E. aureus (385 cepas), seguido de E. coli (209 cepas) y Pseudomona spp. (180 cepas).

Del total de cepas estudiadas la mayoría (626) provenían de infecciones de piel y tejidos blandos, en este grupo se incluyeron infecciones de heridas quirúrgicas; en segundo lugar de frecuencia de infecciones, están las infecciones de vías urinarias (IVU) principalmente procedentes de pacientes hospitalizados en el Hospital San Juan de Dios de Estelí. La mayoría de las cepas de Enterobacter spp., fueron aislados de hemocultivos de neonatos hospitalizados en el HEODRA. Todas las cepas de Shigella spp. y Estreptococos beta hemoliticos del grupo $A$ fueron aislados de pacientes de la comunidad de León; las primeras, de niños menores de 6 años con diarrea y las segundas, de niños menores de 15 años con Faringoamigdalitis.

El perfil de resistencia antimicrobiana se observa en los gráficos siguientes: en la figura No. 2 observamos que Penicilina fue el fármaco de menor efectividad frente a $E$. aureus, sin embargo el hallazgo más importante es lo relativo al perfil de resistencia de E. aureus frente a Meticilina; las cepas aisladas de pacientes de Estelí fueron las de mayor porcentaje de resistencia a este fármaco $(34 \%)$ seguido por los del hospital de León (25\%) y en menor porcentaje Chinandega con $20 \%$.

Las cepas de E. coli mostraron un perfil de resistencia similar en los tres hospitales, fué característico un elevado nivel de resistencia frente a Trimetoprin sulfa, el rango de porcentajes de resistencia fue de $44 \%$ $73 \%$. E. coli aisladas en los hospitales de Estelí

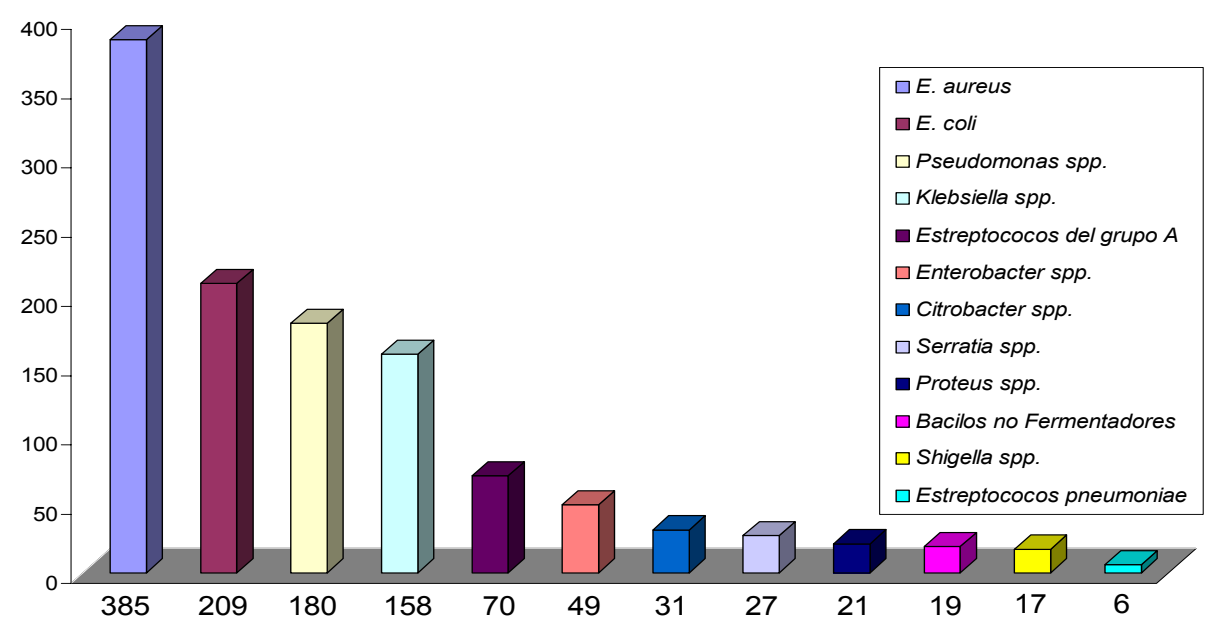

Figura No. 1 Distribución de cepas analizadas 


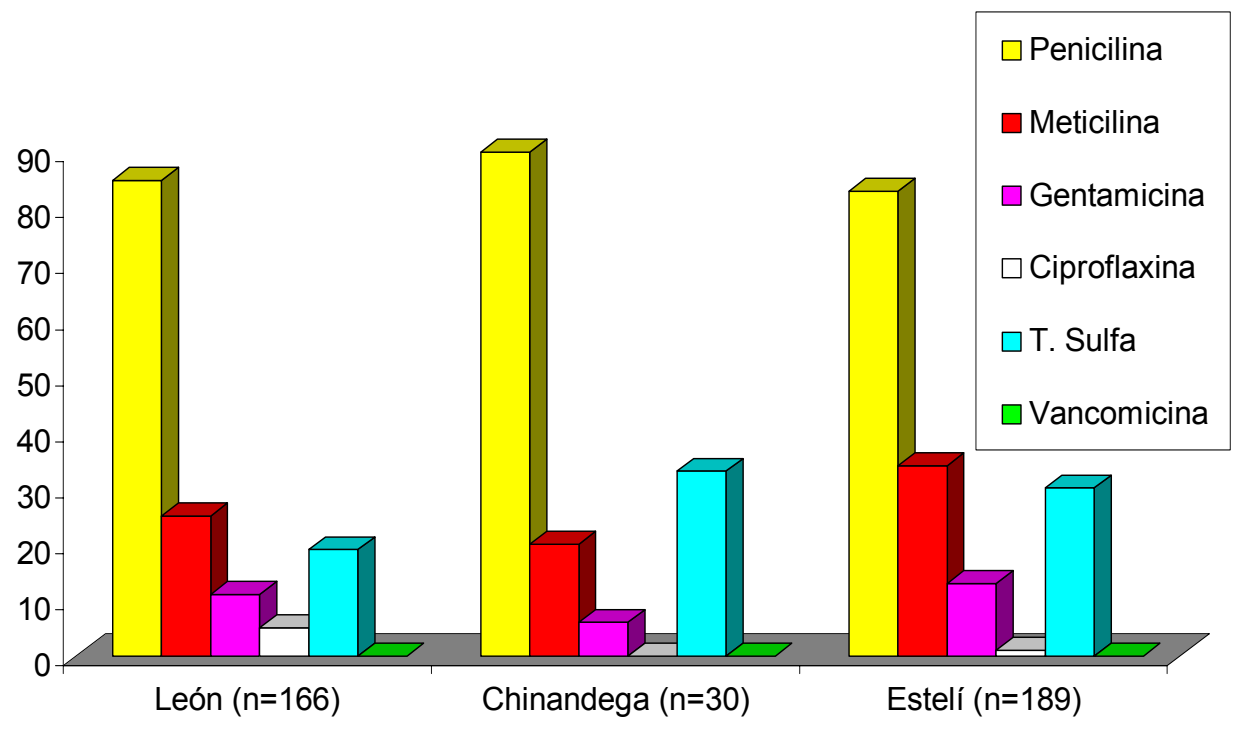

Figura No. 2 Perfil de Resistencia antimicrobiana de Estafilococos aureus.

y León mostraron resistencia en niveles importantes de $37 \%$ y $29 \%$ respectivamente frente a Gentamicina. El perfil de resistencia de E. coli, observado frente a Ceftriaxona es también importante (rango 17\%-22\%). Las quinolonas fueron las de mejor efectividad frente a $E$. coli principalmente las aisladas en León y Chinandega, figura No. 3.

Pseudomonas spp. es una de las especies mas frecuentemente involucradas en infecciones nosocomiales, estas fueron aisladas principalmente en pacientes del hospital de Estelí, Pseudomona aureginosas fueron las especies que presentaron mayor porcentaje de resistencia, a todos los fármacos analizados, sin embargo únicamente el $12 \%$ de las cepas fueron multirresistentes, (resistentes frente a 3 o mas familias de antimicrobianos), figura No. 4.

En las cepas de Klebsiella spp. se observó un comportamiento similar al de Psudomonas en lo relativo al número de cepas con predomino de aislamiento en el Hospital Estelí así como también un perfil de resistencia en el que predominaron las cepas resistentes en el grupo de Estelí, figura No. 5.

Enterobacter spp., Citrobacter spp., Cerratia spp., Proteus $s p p$. y bacilos no fermentadores fueron agrupados como otros bacilos Gram negativos para fines de mostrar en su conjunto el perfil de resistencia observado frente a los antibióticos analizados.

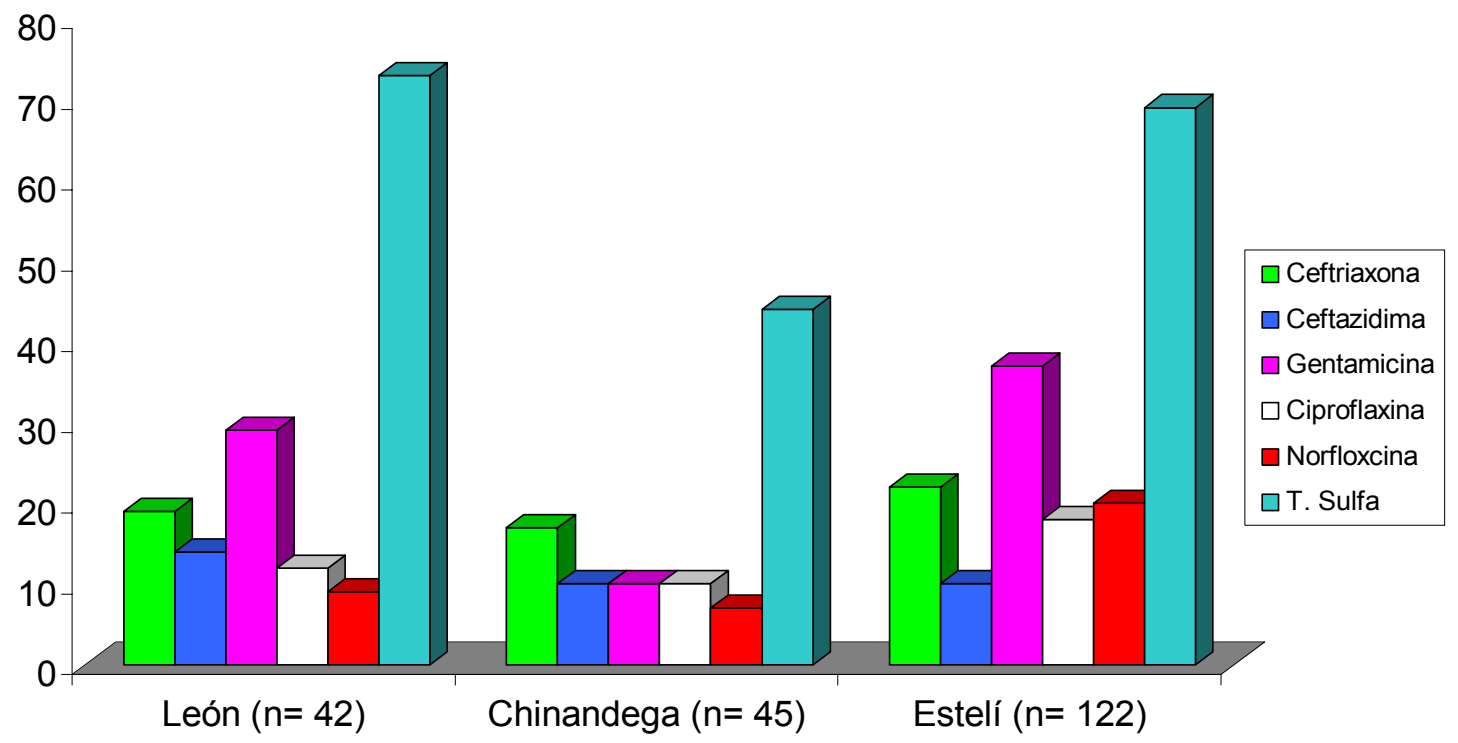

Figura No. 3 Perfil de Resistencia antimicrobiana de E. coli 


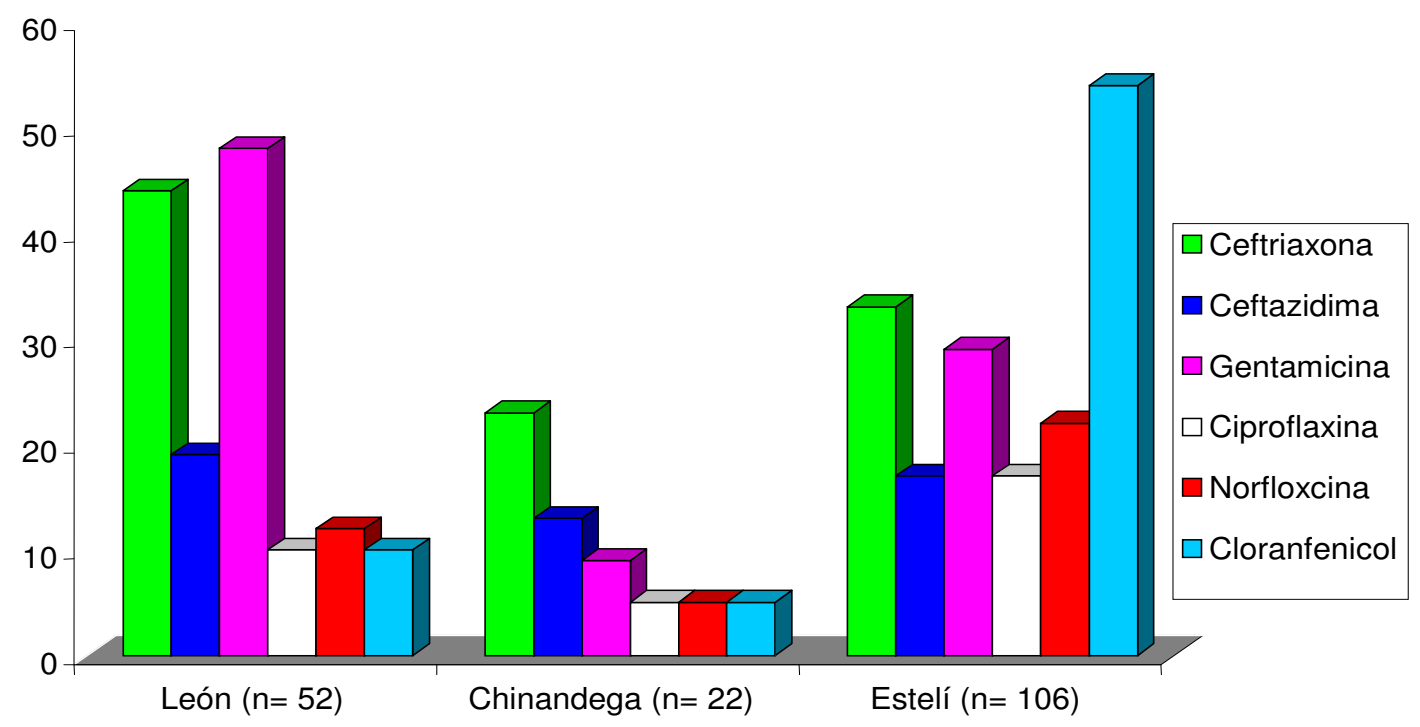

Figura No. 4 Perfil de resistencia de Pseudomonas spp.

La figura No. 6 muestra los resultados obtenidos mismos que son muy similares a los de Klebsiella spp., cabe hacer notar que el predominio de cepas resistentes se encontró entre las cepas de Estelí.

Enterobacter spp. estos fueron las especies con mayor porcentaje de Multirresistencia, y en el $90 \%$ fueron aislados en hemocultivos de neonatos atendidos en UCIN-HEODRA, principalmente con infecciones nosocomiales ocurridas durante el periodo de estudio y un $25 \%$ fueron aislados de muestras obtenidas de niños con diagnostico de sepsis neonatal.

Las cepas que se presentaron en menor número fueron los neumococos, únicamente 6 cepas, en donde 3 correspondían al hospital de León y las otras 3 al hospital de Estelí. Todas fueron sensibles a Penicilina. Las cepas de Shigella spp. incluidas en este estudio fueron obtenidas de pacientes de la comunidad de León, el perfil de resistencia encontrado fue $83 \%$ de las cepas frente a T. sulfa, seguido por $73 \%$ de resistencia frente a Amoxicilina, $35 \%$ a Gentamicina; las quinolonas fueron las de mejor efectividad frente a Shigella spp.

Estreptococos beta hemolíticos del grupo $A$ fueron aislados también en la comunidad siendo sensibles a penicilina y únicamente una cepa fue resistente a Eritromicina.

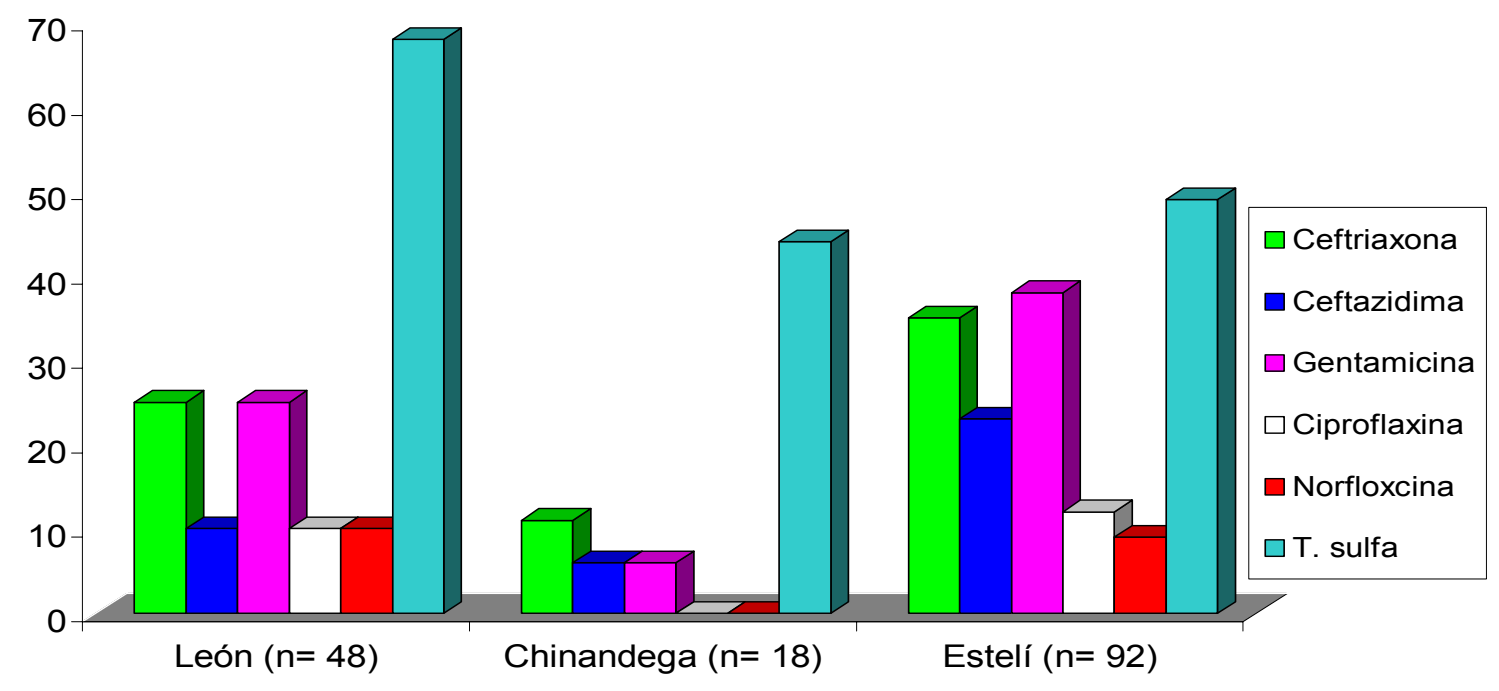

Figura No. 5 Perfil de Resistencia de Klebsiella spp. 


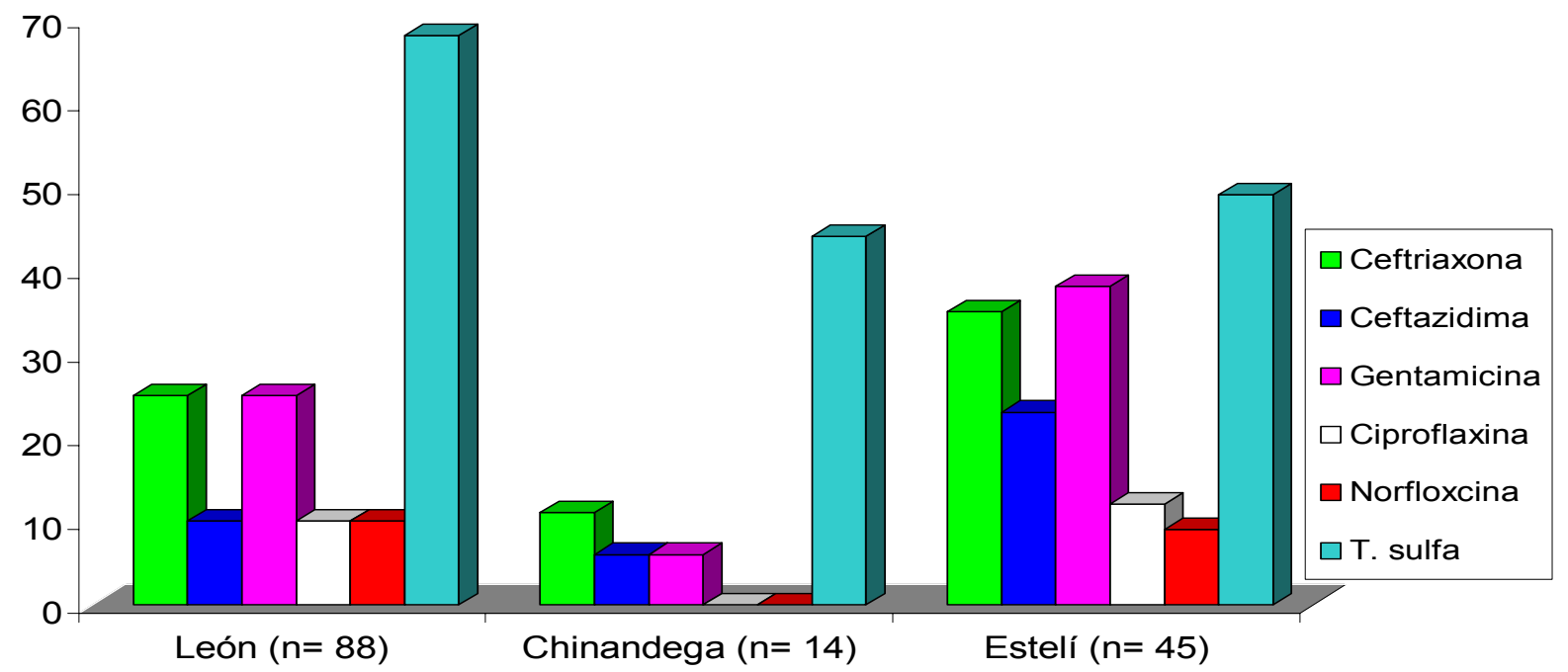

Figura No. 6 Perfil de Resistencia de otros bacilos Gram negativos

\section{DISCUSIÓN}

La resistencia antimicrobiana es detectada en los hospitales Nicaragüenses durante el procedimiento microbiológico estándar para establecer la causa de la infección en el paciente. Sin embargo en la mayoría de los casos el inicio de la antibioticoterapia es usualmente previo al envío de un análisis microbiológico o previo a la obtención de los resultados de este, especialmente por que los resultados son generados en un período no menor de 72 horas. Por lo tanto es válida la utilización de protocolos de manejo de los diferente procesos infecciosos, esto hace que sea fundamental contar con la información oportuna y al día de la epidemiología de la resistencia antimicrobiana, en el lugar donde se está desempeñando la labor médica, de modo que permita elegir el antibacteriano adecuado. Contar con estudios de resistencia antimicrobiana locales son una necesidad por que permite obtener información institucional y nacional respecto de la resistencia en patógenos prevalentes, lo que ayudará en la toma de las decisiones.

Resultados obtenidos en este estudio nos permiten conocer como en el ámbito hospitalario, la resistencia en bacilos Gram negativos a Cefalosporinas de amplio espectro es un fenómeno en crecimiento al igual que Gentamicina que es un antimicrobianoa de amplio uso. Entre los bacilos no fermentadores, Enterobacter emerge como un agente patógeno problemático para tratar por su elevada resistencia, fenómeno que fue observado principalmente en cepas causantes de bacteriemia neonatal. Los valores encontrados en esta vigilancia superan a los determinados en estudios previos realizados en el Hospital de León. ${ }^{[5]}$ La pobre efectividad de T. sulfa contra la mayoría de Gram negativos aislados en Hospital o Comunidad debe ser tomado en consideración al momento de revisar las normas de manejo de infecciones urinarias y en casos de Diarrea causada por Shigella spp.

Otro aspecto importante observado es la evolución de la resistencia a Meticilina de E. aureus, su frecuencia fluctúa entre 20 y $34 \%$. Porcentajes que nos deben comprometer a mantener una vigilancia estrecha. La resistencia a meticilina en E. aureus implica la no efectividad de ninguno de los antibióticos Beta-lactamicos que son los de mayor uso, esto es particularmente alarmante por cuanto E. aureus es uno de los más importantes agentes aislados en hospitales, y estos son sitios que facilitan la dispersión de genes de resistencia tanto en el hospital pero también a la comunidad. Los genes de resistencia son fácilmente transferidos de una especie bacteriana a otra y particularmente entre cocos Gram positivos ha sido ampliamente demostrado ${ }^{[3]}$.

Esperamos que los resultados de este estudio sean de utilidad a la comunidad médica para adecuar las pautas de tratamiento y contribuyan a modificar conductas de riesgo que facilitan la inducción de resistencia, como el abuso en la prescripción de antimicrobianos y hospitalizaciones innecesarias.

Este estudio fue financiado por NeTropica-SIDASAREC y UNAN-León. 


\section{REFERENCIAS}

1. Smith Richard D. \& Coast Joanna, (2002), Antimicrobial resistance: a global response. Bulletin of the World Health Organization, 80.

2. Livermore David M., (2003), Bacterial Resistance: Origins, Epidemiology, and Impact. Clinical Infectious Diseases; 36(Suppl 1):S11-23.

3. Struelens Marc J., (2003), Multidisciplinary antimicrobial management teams: the way forward to control antimicrobial resistance in hospitals. Current Opinion in Infectious Diseases, 16:305-307.

4. National Committee for Clinical Laboratory Standards (NCCLS), (2000), Performance standards for antimicrobial susceptibility testing. M100-S11.

5. Cáceres. M., Carera, E., Palma, A., Berrios, G., Weintraub, A. and Nord C. E. (1999), Antimicrobial susceptibility of anaerobic and aerobic bacteria isolated from mixed infections in Nicaragua. Spanish Journal of Chemotherapy 12:332-339. 